\title{
Evaluation of the impact of polyethylene microbeads ingestion in European sea bass (Dicentrarchus labrax) larvae
}

\author{
Mazurais David ${ }^{1, *}$, Ernande Bruno ${ }^{2}$, Quazuguel Patrick ${ }^{1}$, Severe Armelle ${ }^{1}$, Huelvan Christine ${ }^{1}$, \\ Madec Lauriane ${ }^{1}$, Mouchel Olivier ${ }^{1}$, Soudant Philippe ${ }^{3}$, Robbens Johan ${ }^{4}$, Huvet Arnaud ${ }^{1}$, Zambonino \\ Jose-Luis ${ }^{1}$
}

${ }^{1}$ Ifremer, Centre de Bretagne, LEMAR UMR 6539, Plouzané, France

${ }^{2}$ Ifremer, Channel and North Sea Fisheries Unit, Fisheries Laboratory, BP 699, Boulogne-sur-mer 62321, France

${ }^{3}$ CNRS, IUEM, LEMAR UMR 6539, Plouzané, France

${ }^{4}$ ILVO, Oostende, Belgium3 ILVO, Oostende, Belgium

* Corresponding author : David Mazurais, email address : $\underline{\text { dmazurai@ifremer.fr }}$

\begin{abstract}
:
Microplastics are present in marine habitats worldwide and may be ingested by low trophic organisms such as fish larvae, with uncertain physiological consequences. The present study aims at assessing

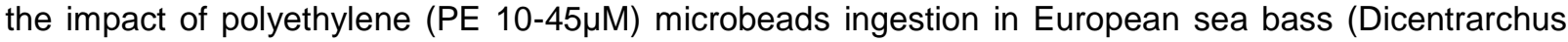
labrax) larvae. Fish were fed an inert diet including 0, 104 and 105 fluorescent microbeads per gram from 7 until 43 days post-hatching (dph). Microbeads were detected in the gastrointestinal tract in all fish fed diet incorporating PE. Our data revealed an efficient elimination of PE beads from the gut since no fluorescent was observed in the larvae after $48 \mathrm{~h}$ depuration. While the mortality rate increased significantly with the amount of microbeads scored per larvae at 14 and $20 \mathrm{dph}$, only ingestion of the highest concentration slightly impacted mortality rates. Larval growth and inflammatory response through Interleukine-1-beta (IL-1 $\beta$ ) gene expression were not found to be affected while cytochromeP450-1A1 (cyp1a1) expression level was significantly positively correlated with the number of microbeads scored per larva at $20 \mathrm{dph}$. Overall, these results suggest that ingestion of PE microbeads had limited impact on sea bass larvae possibly due to their high potential of egestion
\end{abstract}

Keywords : microplastic, fish, larvae, ingestion, survival 


\section{INTRODUCTION}

Microplastics, tiny plastic fragments with diameters of $<5 \mathrm{~mm}$, are widespread and ubiquitous within the marine environment (Lusher, 2015; Thompson, 2015). It is suggested that they are now the most abundant form of solid-waste pollution on Earth (Derraik, 2002; Galgani et al., 2015). Microplastics are originated from the industry, from the domestic use of a wide panel of personal care products which contain microparticles (e.g facial cleansers and toothpaste) (Ghelardini et al., 1996; Zitko and Hanlon, 1991) and from the wastewater of washing machines (Browne, 2015). Waste microplastics also result from the breakdown of larger plastic debris (Andrady, 2011). Polyethylene (PE), polypropylene (PP), polyvinyl chloride (PVC), polystyrene (PS) and polyethylene terephthalate (PET) are among the most widely used polymers in the industry and thereby ultimately found in the ocean (Andrady and Neal, 2009). Presence of microplastics is documented in several species at the base of the food chain such as plankton or filter and deposit feeders because of their microscopic size and their ubiquitous presence (Avio et al., 2015a; Cole et al., 2013; Collignon et al., 2012; Frias et al., 2014; Thompson et al., 2004; Van Cauwenberghe and Janssen, 2014). The plankton, which is a source of food for other animals, could pass microplastics up the food web to top predator species (fish, birds, marine and terrestrial mammals) (Ivar do Sul and Costa, 2014; Wright et al., 2013a).

Several species of fish have been recorded to ingest plastic debris including microplastics (Boerger et al., 2010; Carpenter et al., 1972; Foekema et al., 2013; Lusher et al., 2013). Recent papers reported that microplastics ingestion appears to be common across a range of fish species (pelagic and demersal) from the English Channel (Lusher et al., 2013; Foekema et al., 2013) and Mediterranean sea (Avio et al., 2015b; Deudero and Alomar, 2015; Romeo et al., 2015). It is also documented that all ontogenic phases including early life stages of fish 
can be concerned by plastic debris ingestion (Carpenter et al., 1972; Hoss and Settle, 1990; Possatto et al., 2011). Carpenter et al. (1972), working on fish larvae, reported that of 14 sampled species, 8 contained plastic in their guts. Kartar et al. (1973) found as many as 30 PS particles in the stomachs of flounder, Platichthys flesus, sampled in the Severn Estuary in the United Kingdom. Since fish larval ontogenesis is particularly sensitive to environmental stressors (Houde, 1997), ingestion of plastic by larvae could compromise their survival and may have detrimental consequences on recruitment into the adult population.

Until now, however, there is little information available relative to the biological impacts of microplastic ingestion on fish larval stages. In addition to the chemical effects attributed to organic pollutants that can be adsorbed on the plastic debris, some specific effects of plastic ingestion on marine organisms have been described in the literature. Ingestion of microplastics has been shown to impair feeding, leading to reductions in ingested carbon biomass and energy depletion which result in decreased hatching success in zooplankton (Cole et al., 2015, Lee et al., 2013). It is also suggested that depending on the size of the debris, plastic particles may be retained in the intestine, induce internal injury and clog the digestive system in various marine species including fish (Carpenter et al., 1972; Derraik, 2002). More recently, studies in mussels (Mytilus edulis) indicated that ingested microplastics can also pass through the gut and translocate to the circulatory system (Browne et al., 2008). Their potential presence in tissues allows a glimpse of the effects on essential physiological functions other than the digestive one. In mussels, ingestion of non-contaminated microplastics has been shown to induce immunological effects and inflammatory response (Avio et al., 2015a, Von Moos et al., 2012; Wright et al., 2013b). Concerning fish species, studies from Oliveira et al. (2013) suggested adverse effects of virgin microplastics in neurofunction of the common goby Pomatoschistus microps. Rochman et al. $(2013,2014)$ 
demonstrated early signs of endocrine disruption as well as hepatic stress in adult medaka Oryzias latipes after ingestion of virgin polyethylene. In contrast, recent work performed on larvae of invertebrates (sea urchin, Tripneustes gratilla) indicated very limited biological impact of microplastics ingestion suggesting that effect of plastic ingestion could be species and/or stage specific and can depend on the nature of the ingested plastic (Kaposi et al., 2014).

In the present study, we investigated the impact of per os administration of PE microbeads on European sea bass (Dicentrarchus labrax) larvae. Sea bass, with most marine fish species, exhibits an extended pelagic planktotrophic larval period and thereby potentially encounters and ingests microplastic particles during its development. Using an inert diet incorporating PE microbeads, the main objectives of our study were to assess (i) the effective retention of microplastics in the gut of sea bass larvae and (ii) the potential impact of microplastic ingestion on their survival, growth and some physiological parameters. The inflammatory response, suggested to be impacted in other species (Von Moos et al., 2012; Wright et al., 2013b), was addressed through investigation of a proxy of this pathway, the Interleukin-1 beta (IL-1 $\beta$ ) gene expression (Ogryzko et al., 2014). Potential chemotoxic effect of fluorescent PE microbeads possibly due to hazardous decomposition by-products induced in digestive tract was tackled through the analysis of the expression of cytochrome-P450-1A1 (cyplal) involved in the biotransformation of toxicants. 


\section{MATERIALS AND METHODS}

\subsection{Animals and experimental diets}

European sea bass larvae were provided by the marine farm Aquastream (Ploemeur, France) and reared from 2 days after hatching (dph) to 45 dph at IFREMER, Centre de Brest (France). Larvae were distributed into 18 conical fiberglass tanks $(35 \mathrm{~L})$ at $3 \mathrm{dph}$, with initial stocking density of 60 larvae $\cdot \mathrm{L}^{-1}$ and were reared according to Darias et al., (2010) until $45 \mathrm{dph}$. Briefly, the tanks were supplied with running seawater at $20^{\circ} \mathrm{C}$, which had been filtered through a sand filter and then passed successively through a tungsten heater and degassing column packed with plastic rings. To prevent any dumping of PE microbeads to waste water and subsequently at sea, outflow of seawater was filtered on a $1 \mu \mathrm{m}$ filter renewed every week and then burned by a waste management company.

From 7 to $43 \mathrm{dph}$, larvae were fed on microparticulate diets (WO 0064273) prepared in our laboratory as described by Cahu et al. (2003), 6 replicate tanks each, including 0 (control, C), $10^{4}$ (i.e. $1.2 \mathrm{mg} ; 1 \mathrm{X}$ ) or $10^{5}$ (i.e. $12 \mathrm{mg} ; 10 \mathrm{X}$ ) fluorescent microbeads of polyethylene (\#UVPMS-BR, mix of 10-45 $\mu \mathrm{m}, 1.050 \mathrm{~g} / \mathrm{cc}$, Cospheric, Santa Barbara, CA, USA) per gram of diet. The dietary ingredients, including microbeads, were mixed with water, pelletized, and dried at $50^{\circ} \mathrm{C}$ for $60 \mathrm{~min}$. The pellets were sieved to obtain particles with size lower than 400 $\mu \mathrm{m}$. The concentration of microbeads in the three diets was confirmed by counting fluorescent beads under microscope. The larvae were fed in excess with belt feeders $16 \mathrm{~h}$ per day (10:00AM-02:00 AM). The fluorescent PE microbead concentrations incorporated in the feed were used to correspond to high environmentally relevant concentration of microplastics that larvae could ingest in the wild environment (see discussion part).

Non-ingested food and faeces were collected using a filter to avoid dissemination of microbeads in effluent. From 43 to 45 dph, all groups were fed control diet. 
Experiments were conducted within IFREMER facilities having authorization for animal experimentation. Present work was performed in accordance with French and European policies and guidelines of the IFREMER institute (Agreement number: 01964.01).

\subsection{Monitoring of microbeads ingestion and retention}

The presence of fluorescent microbeads in European sea bass larvae was followed by microscopic analysis. At 14, 20, 34 (exposure phase) and 45 (depuration phase) dph, 20 larvae per tank (120 per group) were randomly sampled, fixed in ethanol-formalin-acetic acid (ethanol 95\% 6V; formaldehyde 40\% 3V, glacial acetic acid, 1V) for 48 hours then immersed in ethanol $(100 \%)$ for microscope examination. The number of larvae containing microbeads was scored and the number of beads detected per larvae was counted.

\subsection{Survival and growth}

Survival in each experimental group (mean of the 6 replicates) was assessed by scoring the number of alive larvae at the end of the experiment ( $45 \mathrm{dph})$ and by considering the initial number of larvae as well as amount of larvae sampled in each tank for analysis. 50-60 larvae randomly sampled at 20,27, 34 and 43 dph in each of the 6 replicated tanks were weighed to determine larval growth for each experimental group.

\subsection{RNA extraction, cDNA synthesis and real time PCR}

Total RNA was extracted from pools of whole larvae (1 pool per tank) at 27 and 43 dph with Extract-All (Eurobio, France), following manufacturer's instructions. Thirty larvae were sampled per pool at $27 \mathrm{dph}$ to get around $100 \mathrm{mg}$ of fresh tissue while 7 to 10 larvae were necessary at $43 \mathrm{dph}$. Potential DNA contaminants were removed from extracted RNA by using RTS DNase ${ }^{\mathrm{TM}}$ kit (Mo bio laboratories, Carlsbad, USA) following manufacturer's 
instructions. RNA quantity and quality were next assessed by spectrophotometry (NanoDrop ND-1000, Nanodrop Labtech, France) and gel electrophoresis (2100 Bioanalyzer, Agilent Technologies, Santa Clara, USA). All extracted RNA exhibited RIN (RNA Integrity Number) greater than 7 .

Complementary DNA (cDNA) synthesis was performed with $500 \mathrm{ng}$ of the resulting total RNA using the iScript ${ }^{\mathrm{TM}}$ cDNA Synthesis Kit (Bio Rad, Hercules, CA, USA).

Relative quantification of target genes (IL-1 $\beta$ and cyplal) expression was performed by quantitative PCR (q-PCR) using the CFX96 real time system ${ }^{\mathrm{TM}}$ (Bio-Rad). Analyses were performed on $5 \mu$ l of the diluted cDNA (1:20) using SsoAdvanced ${ }^{\mathrm{TM}}{ }_{\mathrm{SYBR}}{ }^{\circledR}$ Green Supermix (Bio-Rad), in a total PCR reaction volume of $15 \mu$, containing $200 \mathrm{nM}$ of each primer. Primers were designed from sequences available in NCBI (http://www.ncbi.nlm.nih.gov/) and Sigenae (http:// http://www.sigenae.org/) databases (accession numbers mentioned in Table 1). Thermal cycling was initiated with incubation at $98^{\circ} \mathrm{C}$ for 2 min for hot start Sso $7 \mathrm{~d}$-fusion polymerase activation. Forty cycles of PCR were performed, each one consisting of 2 successive steps: heating at $95{ }^{\circ} \mathrm{C}$ for $5 \mathrm{~s}$ for denaturing, and at $60{ }^{\circ} \mathrm{C}$ for $20 \mathrm{~s}$ for annealing and extension. Following the final PCR cycle, melting curves were systematically monitored $\left(0.5^{\circ} \mathrm{C}\right.$ increments from $65^{\circ} \mathrm{C}$ to $\left.95^{\circ} \mathrm{C}\right)$ to ensure that only one fragment was amplified. Each PCR run included technical triplicates for each sample and negative controls (reverse transcriptase free samples, RNA-free samples). For each primer pairs, efficiency (E) of PCR was measured by the slope of a standard curve using serial dilutions of a pool of cDNA from the present experiment. E ranged from $95 \%$ to $100 \%$ in the present qPCR analysis.

Relative quantification of the target gene transcript was performed using the Bio-Rad CFX Manager 3.1 software. Quantification of the target gene transcripts was performed using the elongation factor $1 \alpha(\mathrm{EF} 1 \alpha)$ and glyceraldehyde-3-phosphate dehydrogenase (GAPDH) as 
reference genes since they exhibit high stability values (Coefficient of Variation $<0.25$; Mvalues $<0.5$ ) between samples (revealed by "target stability value" option of the Bio-Rad CFX Manager 3.1 software).

\subsection{Statistical analysis}

All data were analyzed using generalized linear models with varying underlying distribution depending on data type and diagnostics. A detailed description of the analyses can be found in Annex.

Percentages of larvae containing microbeads were compared between groups throughout exposure time by using a logistic regression with Group (C, 1X, 10X) and Stage (14, 20, 34, and $45 \mathrm{dph}$ ) as explanatory factors, followed by a post hoc multiple comparison test (Hothorn et al., 2008). Significance of the effects was tested by likelihood ratio tests (LRTs) between nested models respecting marginality of the effects (type II tests; Fox and Weisberg, 2011).

The effect of microbeads exposure on larval mortality was assessed by analyzing the trend of the number of alive larvae with time, the slope representing instantaneous mortality rate, using negative binomial regression. The effect of microbead concentration on mortality rate was assessed by considering the effect of (i) Group as explanatory and (ii) the average number of beads per larva $\left(b_{S}\right)$ measured at various stages $(S=14,20$ or $34 \mathrm{dph})$ as explanatory continuous variable. Significance of the effects was again tested by LRTs between nested models. For the Group effect, the LRT was followed by a post-hoc multiple comparison test (Hothorn et al., 2008) to assess which groups differed from one another.

The impact of microbeads exposure on body weight gain was assessed using an ordinary linear model with both Stage $(20,27,34$ and 43dph) as an explanatory continuous covariable and Group as explanatory factor. 
204 Finally, the effect of microbeads exposure on $I L-1 \beta$ and cyplal gene expression at 27 and 43

205 dph was evaluated by an ordinary linear model with (i) Group as explanatory factor and (ii) 206 the average number of beads per larva $b_{S}$ measured at various stages as explanatory 207 continuous variable.

208 For all analyses, the underlying hypotheses were verified, diagnostics based on residuals were 209 performed and the significance threshold was fixed at 0.05 .

210 


\section{RESULTS}

\subsection{Tracking PE beads ingestion}

214

Larvae containing microbeads were only found in the two groups (1X, 10X) exposed to PE during the exposure period, i.e. at 14, 20 and 34 dph (Fig. 1; Fig. 2). The average number of beads detected per larva ranged from $1.4( \pm 0.33 \mathrm{SD})$ in group $1 \mathrm{X}$ to $3.3( \pm 0.19 \mathrm{SD})$ in group 10X. Most of the retained microbeads have a particle size around $45 \mu \mathrm{m}$ even if it was difficult to address quantitatively this question since beads could cluster together. In contrast, two days after the end of exposure period ( $45 \mathrm{dph}$ ), no more beads were detected in larvae from any experimental group (Fig. 1). Given that the number of microbeads per larva was 0 in the control treatment $\mathrm{C}$ and at $45 \mathrm{dph}$, these two factor levels were excluded from the logistic regression analysis. The percentages of larvae with microbeads in their digestive tract appeared significantly higher in group $10 \mathrm{X}$ (average of $68 \% \pm 16 \% \mathrm{SD}$ ) compared to group $1 \mathrm{X}$ (average of $35 \% \pm 7 \% \mathrm{SD}$ ) throughout exposure period [Fig.1, Group effect $(p<0.001)$; post-hoc test $1 \mathrm{X}$ vs. $10 \mathrm{X}: \mathrm{z}=-4.064, p<0.001]$. No significant effect of the interaction between group and stage was identified. The amount of larvae containing microbeads decreased significantly at $34 \mathrm{dph}$ as compared to previous stages, $14 \mathrm{dph}$ and $20 \mathrm{dph}$ [Stage effect $(p=0.012)$, Fig. 1 ; post-hoc test: 14 dph vs. 30 dph: $\mathrm{z}=2.858, p=0.016,20$ dph vs. 34 dph: $\mathrm{z}=2.686, p=0.025]$.

\subsection{Mortality rates}

The average cumulative mortality scores at 45 dph ranged from $29 \%$ to $31 \%$ in the groups $1 \mathrm{X}$ and Control, respectively, to $44 \%$ in group $10 \mathrm{X}$ (Fig. 3). A Group effect on larval instantaneous mortality rate was detected $(\chi 2=9.776 ;$ p-value $=0.008 ;$ Fig. 3$)$ and the subsequent post-hoc multiple comparison test revealed that the instantaneous mortality rate of 
group 10X $[(13.4 \pm 1.4) \times 10-3$ day-1] was significantly higher of about $54 \%$ than those of group $\mathrm{C}[(8.7 \pm 1.4) \times 10-3$ day-1, $p=0.015]$ and $1 \mathrm{X}[(8.0 \pm 1.5) \times 10-03$ day-1, $p=0.006]$. Moreover, the instantaneous mortality rate increased significantly with the amount of beads scored per larvae at 14 and $20 \mathrm{dph}$ but not at $34 \mathrm{dph}$ (Fig. 4). The increases of instantaneous mortality rates per bead were of $21.9 \%$ and $21.2 \%$ relative to mortality rate without bead at 14 dph and $20 \mathrm{dph}$, respectively.

\subsection{Growth}

Fish from all experimental groups exhibited exponential growth, as is typical during larval development (Fig. 5). No significant effect of PE beads ingestion on the growth rate was observed. The mean weight of larvae in the $10 \mathrm{X}$ group was only marginally $(\mathrm{p}=0.097)$ higher from 34 dph onwards.

\subsection{Gene expression}

No significant change in $I L-1 \beta$ and cyplal gene expression was detected across Groups, be it at 27 or $43 \mathrm{dph}$. However, the expression of cyplal at $43 \mathrm{dph}$ (but not at $27 \mathrm{dph}$ ) increased significantly with the average number of beads per larva measured at $20 \mathrm{dph}(+35 \%$ for 4 beads, $p=0.016)$ and marginally with those measured at $14 \mathrm{dph}(+27 \%$ for 4 beads, $p=0.059)$ and $34 \mathrm{dph}(+17 \%$ for 4 beads, $p=0.074$; Fig. 6$)$. At the same time, microbeads ingestion did not induce any significant effects on $I L-1 \beta$ expression (data not shown). 


\section{DISCUSSION}

In order to evaluate the biological impact of microplastics ingestion on marine fish larvae, the

effects of per os administration of PE microbeads in European sea bass were assessed under laboratory conditions. Among the widely used polymers in the industry, PE is one of the most abundant in the natural environment and thereby also found in the ocean (Andrady and Neal, 2009). In the present study, the fluorescent PE microbead concentrations incorporated in the feed were used to reveal a potential physiological response of fish during a sensitive period of to $60 \%$ in dry weight (Barahona-Fernandes and Gerard, 1981) and the concentration of microbeads included in the present diets (10 to 100 microbeads/mg of diet), we can estimate that individual fish larvae weighing on average $4 \mathrm{mg}$ ingested around 20 beads (group 1X) and 200 beads (group 10X) with a diameter lower than $45 \mu \mathrm{m}$ per day. Based on the data from Desforges et al (2015) suggesting that 2-7 microplastic particles $(>200 \mu \mathrm{m}) /$ day could be ingested by individual juvenile salmon in coastal British Columbia, we assume that the quantities of microbeads ingested in the present study correspond to high environmentally relevant concentrations of microplastics that larvae may encounter in the wild environment. As expected, the proportion of larvae containing microbeads in their gut and the quantity of microbeads per larva depended on the concentration of microbeads included in the diet. On average, at any given time of larval development, around $70 \%$ and $35 \%$ of the larvae from

277 group $10 \mathrm{X}$ and $1 \mathrm{X}$ respectively contained beads in their gut. Globally, only one to four microbeads per larva were detected on average. Thus, considering i) the concentration of microbeads in the diets (10 to 100 microbeads/mg of diet), ii) the quantity of food ingested per larvae in a day ( $<2 \mathrm{mg}$, depending on developmental stage), iii) the fact that larvae were 
time in fish larvae (from 2 hours to 10 hours depending on species and feeding protocol) (Govoni et al., 1986), these data indicate high potential of egestion of PE microbeads from 10 to $45 \mu \mathrm{m}$ in sea bass larvae. This hypothesis is confirmed by the fact that no more microbeads were found in the gut of larvae at $45 \mathrm{dph}$, i.e. two days after the end of the exposure period, and by the fact that microbeads were found in large quantities in faeces (data not shown). The latter excludes the possibility that larvae regurgitate significant quantities of microbeads. However, this conclusion on the fast transit of PE microbeads through digestive tract of fish larvae warrants caution since the high egestion rate observed in the present study could be related to the smooth and spherical characteristics of beads which are different from plastic debris such as fibers or fragments of varying roughness found in the natural environment (Lusher et al., 2013).

Despite this high egestion potential in sea bass larvae, the present study indicates that the digestive tract contained microbeads in all fish fed diet incorporating PE. This data suggests that in a highly contaminated environment, microplastics found in the zooplankton (Cole et al., 2013) could be ingested by fish larvae, which in turn can be eaten by predators before egestion. Many kinds of invertebrates such as crustaceans, ctenophores, medusae, or vertebrates such as fishes are known larval fish predators (Paradis et al., 1996). The ingested microplastics could then be retained by predators having more complex digestive tracts (e.g. gastric mill in crustacean) (Murray and Cowie, 2011), which may have detrimental implications for bioaccumulation, especially if any associated chemical contaminants that are transferred have the potential for biomagnification (Teuten et al., 2009). This scenario of trophic transfer in the wild is dependent on the rate of plastic contamination in plankton and on the nature (shape and roughness) of microplastics ingested by fish larvae that will determine the resident time in its digestive tract. 
Even if larval mortality rate increased with the number of PE microbeads scored per larvae until $20 \mathrm{dph}$, only fish exposed to the highest concentration of beads exhibited slight but significantly higher mortality rates. This slight impact is likely to be explained by the apparent high potential of microbeads egestion from the gut (discussed above). In different marine organisms including fish species (Laist, 1987), mortality has been indeed shown to be potentially induced by an obstruction of the gastrointestinal tract because of knots or clumps of plastic debris. The positive correlation found between mortality rates and the level of PE microbeads ingestion during the first stages of sea bass larval development can be related to the diameters of their esophageal, gastric and intestinal lumens that are narrower than in older stages. While the diameter of the anterior intestine is around $60-80 \mu \mathrm{m}$ at $29 \mathrm{dph}$ in European sea bass (Giffard-Mena et al., 2006), it is conceivable that microbeads of $45 \mu \mathrm{m}$ or less used in the present work, when ingested in very high quantities, could block the lumen at earlier stages of development. Microscopic observation of dead larvae during the first 20 days of development may have confirmed the occurrence of gut obstruction. In group 10X, mortality of smaller larvae during the first developmental stages could explain the tendency towards a heavier weight observed from 34 dph onwards. Additional experiments using larger PE sizes $(>45 \mu \mathrm{m})$ with different shape and ruggedness would allow to reveal gut obstruction-induced mortality, particularly during early larval stages.

As demonstrated in other species such as seabirds, marine copepod and marine worms (Cole et al., 2015; Ryan, 1988; Wright et al., 2013b), decreased food consumption resulting in depleted energy reserves and lower growth rate could be expected in sea bass larvae exposed to microplastics. Conversely, per os administration of PE microbeads in sea bass larvae had no significant impacts on the growth rate. This data, suggesting that PE microbeads ingestion did not induce feeding impairment and energetic depletion can probably be related to the high potential of microbeads egestion throughout sea bass larval development. 
More generally, the absence of a substantial effect on growth suggests a limited impact of PE microbeads ingestion on fish larvae physiology. Indeed, growth rate is usually used for predicting response of fish populations to environmental stress since it is a temporally integrative proxy for an organism's fitness (Crossin et al., 2014). Accordingly, whereas an inflammatory response was observed in blue mussel (Mytilus edulis L) and in marine worms (Arenicola marina) exposed to microplastics (von Moos et al., 2012; Wright et al., 2013b) no indication of inflammation was demonstrated in sea bass larvae through the $I L-1 \beta$ biomarker. $I L-1 \beta$ is typically considered as the 'gatekeeper' of inflammation that drives the early response to injury in several organisms including fish species (Ogryzko et al., 2014). Again no strong conclusions can be drawn considering the smooth and spherical shape of administrated PE microbeads since the high potential of egestion of beads used in the present study could explain the absence of inflammatory response in sea bass larvae. Indeed, it has been shown in mussel that the indications of inflammatory response (formation of granulocytomas) significantly increased with longer residence time of microplastic in the digestive gland (von Moos et al., 2012). Moreover, the spherical shape may cause little injury and weak gut inflammatory reaction whereas microplastics found in the digestive tract of fish sampled in the marine environment can consist of very various shapes and ruggedness (Avio et al., 2015b; Collard et al., 2015), some of which could be far more abrasive and angular than calibrated spheres.

Finally, our data indicate a significant correlation between the quantity of plastic microbeads scored in larvae at $20 \mathrm{dph}$ and the gene expression of cyplal at $43 \mathrm{dph}$. Cyplal, whose expression is mostly enhanced by AhR-compatible toxicants (e.g., polycyclic aromatic hydrocarbons, dioxins, alkylphenols...), is considered as a key actor of toxicant biotransformation in many species including teleosts (Sarasquete and Segner, 2000). 
However, as virgin PE microbeads were used in the present experiment, no coingestions of

357 AhR-compatible toxicants in reasonable quantities with PE are expected. Base on material safety data sheet of PE microbeads (Cospheric, 2012), acidic conditions within the gut of fish larvae may produce hazardous decomposition by-products such as oxides of sulfur. It cannot be ruled out that such oxidation products regulate cyplal expression as already observed in rats (Qin and Meng, 2010). Another possibility is that the shifts in Cyplal expression relate to metabolic modulation upon development and/or exposure without biotransformation mechanisms.

\section{In conclusion, present work revealed that ingestion of virgin PE microbeads has a limited} impact on traits (survival and body growth) directly linked to fitness in European sea bass larvae. The apparent limited impact is consistent with data observed in other marine organisms (Kaposi et al., 2014; Van Cauwenberghe et al., 2015).

However, the present study does not pretend to reflect perfectly the impact of microplastic ingestion in natural populations. The shapes as well as the biological and chemical loads of plastic debris found in the natural environment are generally more harmful. Specific effects of such environmental microplastic debris should be further tested. Finally, this study confirms experimentally the ability of fish larvae to ingest microplastic debris when they prey on plankton that has been previously contaminated or entangled (Frias et al., 2014). In the same way, fish larvae are themselves highly vulnerable to predation and may contribute to the contamination of higher trophic level organisms.

\section{ACKNOWLEDGMENTS}

This work was carried out within the frame of the MICRO project (EU INTEREG IVA - Seas (MICRO 09-002-BE). 


\section{REFERENCES}

Andrady, A.L., Neal, M.A., 2009. Applications and societal benefits of plastics. Philos Trans R Soc Lond B Biol Sci 364, 1977-1984.

Andrady, A.L., 2011. Microplastics in the marine environment. Mar Pollut Bull 62, 1596-1605.

Avio, C.G., Gorbi, S., Milan, M., Benedetti, M., Fattorini, D., d'Errico, G., Pauletto, M., Bargelloni, L., Regoli, F., 2015a. Pollutants bioavailability and toxicological risk from microplastics to marine mussels. Environ Pollut 198, 211-222.

Avio, C.G., Gorbi, S., Regoli, F., 2015b. Experimental development of a new protocol for extraction and characterization of microplastics in fish tissues: First observations in commercial species from Adriatic Sea. Mar Environ Res. 2015 Jul 2. pii: S01411136(15)30003-9. doi: 10.1016/j.marenvres.2015.06.014.

Barahona-fernandes, M.H., Gerard, C., 1981. Daily food intake of reared larvae of the european seabass (dicentrarchus labrax L.) Statistical analysis and modelling. COB 639, 912.

Boerger, C.M., Lattin, G.L., Moore, S.L., Moore, C.J., 2010. Plastic ingestion by planktivorous fishes in the North Pacific Central Gyre. Mar Pollut Bull 60, 2275-2278.

Browne, M.A., Dissanayake, A., Galloway, T.S., Lowe, D.M., Thompson, R.C., 2008. Ingested microscopic plastic translocates to the circulatory system of the mussel, Mytilus edulis (L). Environ Sci Technol 42, 5026-5031.

Browne, M.A., 2015. Sources and Pathways of Microplastics to Habitats, in: Bergmann, M., Gutow, L., Klages, M. (Eds.), Marine Anthropogenic Litter. Springer International Publishing, pp. 229-244.

Cahu C., Zambonino-Infante J. and Takeuchi T., 2003. Nutritional components affecting skeletal development in fish larvae, Aquaculture 227, 245-258.

Carpenter, E.J., Anderson, S.J., Harvey, G.R., Miklas, H.P., Peck, B.B., 1972. Polystyrene spherules in coastal waters. Science 178, 749-750.

Cole, M., Lindeque, P., Fileman, E., Halsband, C., Goodhead, R., Moger, J., Galloway, T.S., 2013. Microplastic ingestion by zooplankton. Environ Sci Technol 47, 66466655 .

Cole, M., Lindeque, P., Fileman, E., Halsband, C., Galloway, T.S., 2015. The impact of polystyrene microplastics on feeding, function and fecundity in the marine copepod Calanus helgolandicus. Environ Sci Technol 49, 1130-1137. 
Collard, F., Gilbert, B., Eppe, G., Parmentier, E., Das, K., 2015. Detection of Anthropogenic Particles in Fish Stomachs: An Isolation Method Adapted to Identification by Raman Spectroscopy. Arch Environ Contam Toxicol. 69, 331-339.

Collignon, A., Hecq, J.H., Glagani, F., Voisin, P., Collard, F., Goffart, A., 2012. Neustonic microplastic and zooplankton in the North Western Mediterranean Sea. Mar Pollut Bull 64, 861-864.

\section{Cospheric, 2012. http://www.cospheric.com/Images/PDFs/UVPMS-BR-MSDS.pdf}

Crossin, G.T., Cooke, S.J., Goldbogen, J.A., Phillips, R.A., 2014. Tracking fitness in marine vertebrates: current knowledge and opportunities for future research. Marine Ecology Progress Series 496, 1-17.

Darias, M.J., Mazurais, D., Koumoundouros, G., Glynatsi, N., Christodoulopoulou, S., Huelvan, C., Desbruyeres, E., Le Gall, M.M., Quazuguel, P., Cahu, C.L., Zambonino-Infante, J.L., 2010. Dietary vitamin D3 affects digestive system ontogenesis and ossification in European sea bass (Dicentrachus labrax, Linnaeus, 1758). Aquaculture 298, 300-307.

Derraik, J.G., 2002. The pollution of the marine environment by plastic debris: a review. Mar Pollut Bull 44, 842-852.

Desforges, J.P., Galbraith, M., Ross, P.S., 2015. Ingestion of Microplastics by Zooplankton in the Northeast Pacific Ocean. Arch Environ Contam Toxicol. 69, 320-330.

Deudero, S., Alomar, C., 2015. Mediterranean marine biodiversity under threat: Reviewing influence of marine litter on species. Mar Pollut Bull. 98, 58-68.

Foekema, E.M., De Gruijter, C., Mergia, M.T., van Franeker, J.A., Murk, A.J., Koelmans, A.A., 2013. Plastic in north sea fish. Environ Sci Technol 47, 8818-8824.

Fox, J., Weisberg, S., 2011. An R Companion to Applied Regression. 2nd ed. Los Angeles, USA: SAGE Publications.

Frias, J.P., Otero, V., Sobral, P., 2014. Evidence of microplastics in samples of zooplankton from Portuguese coastal waters. Mar Environ Res 95, 89-95.

Galgani, F., Hanke, G., Maes, T., 2015. Global Distribution, Composition and Abundance of Marine Litter, in: Bergmann, M., Gutow, L., Klages, M. (Eds.), Marine Anthropogenic Litter. Springer International Publishing, pp. 29-56..

Ghelardini, C., Bartolini, A., Galeotti, N., Teodori, E., Gualtieri, F., Gregory, M.R., 1996. Plastic 'Scrubbers' in Hand Cleansers: a Further (and Minor) Source for Marine Pollution Identified. Mar Pollut Bull 32, 867-871.

Giffard-Mena, I., Charmantier, G., Grousset, E., Aujoulat, F., Castille, R., 2006. Digestive tract ontogeny of Dicentrarchus labrax: implication in osmoregulation. Dev Growth Differ 48, 139-151. 
Govoni, J., Boehlert, G., Watanabe, Y., 1986. The physiology of digestion in fish larvae. Environmental Biology of Fishes 16, 59-77.

Hoss, D.E., Settle, L.R., 1990. Ingestion of plastics by teleost fishes. , in: R.S., S., M.L., G. (Eds.), Proceedings of the second international conference on marine debris. US Department of Commerce, NOAA Technical Memo, Honolulu, HI, p. $693 \hat{a}^{\wedge}$ '709.

Hothorn, T., Bretz, F., Westfall, P., 2008. Simultaneous inference in general parametric models. Biom J 50, 346-363.

Houde, E.D., 1997. Patterns and trends in larval-stage growth and mortality of teleost fish. Journal of Fish Biology 51, 52-83.

Ivar do Sul, J.A., Costa, M.F., 2014. The present and future of microplastic pollution in the marine environment. Environ Pollut 185, 352-364.

Kaposi, K.L., Mos, B., Kelaher, B.P., Dworjanyn, S.A., 2014. Ingestion of microplastic has limited impact on a marine larva. Environ Sci Technol 48, 1638-1645.

Kartar, S., Milne, R.A., Sainsbury, M., 1973. Polystyrene waste in the Severn Estuary. Mar Pollut Bull 4, 144.

Laist, D.W., 1987. Overview of the biological effects of lost and discarded plastic debris in the marine environment. Mar Pollut Bull 18, 319-326.

Lee, K.-W., Shim, W.J., Kwon, O.Y., Kang, J.-H., 2013. Size-Dependent Effects of Micro Polystyrene Particles in the Marine Copepod Tigriopus japonicus. Environmental Science \& Technology 47, 11278-11283.

Lusher, A.L., McHugh, M., Thompson, R.C., 2013. Occurrence of microplastics in the gastrointestinal tract of pelagic and demersal fish from the English Channel. Mar Pollut Bull 67, 94-99.

Lusher, A.L., 2015. Microplastics in the Marine Environment: Distribution, Interactions and Effects, in: Bergmann, M., Gutow, L., Klages, M. (Eds.), Marine Anthropogenic Litter. Springer International Publishing, pp. 245-307.

Murray, F., Cowie, P.R., 2011. Plastic contamination in the decapod crustacean Nephrops norvegicus (Linnaeus, 1758). Mar Pollut Bull 62, 1207-1217.

Ogryzko, N.V., Hoggett, E.E., Solaymani-Kohal, S., Tazzyman, S., Chico, T.J., Renshaw, S.A., Wilson, H.L., 2014. Zebrafish tissue injury causes upregulation of interleukin-1 and caspase-dependent amplification of the inflammatory response. Dis Model Mech 7, 259-264.

Oliveira, M., Ribeiro, A., Hylland, K., Guilhermino, L., 2013. Single and combined effects of microplastics and pyrene on juveniles (0+group) of the common goby Pomatoschistus microps (Teleostei, Gobiidae). Ecological Indicators 34, 641-647. 
Paradis, A.R., Pepin, P., Brown, J.A., 1996. Vulnerability of fish eggs and larvae to predation: Review of the influence of the relative size of prey and predator. Canadian Journal of Fisheries and Aquatic Sciences 53, 1226-1235.

Possatto, F.E., Barletta, M., Costa, M.F., do Sul, J.A., Dantas, D.V., 2011. Plastic debris ingestion by marine catfish: an unexpected fisheries impact. Mar Pollut Bull 62, 10981102.

Qin, G., Meng, Z., 2010. Sulfur dioxide and benzo(a)pyrene modulates CYP1A and tumor-related gene expression in rat liver. Environ Toxicol 25, 169-179.

Rochman, C.M., Hoh, E., Kurobe, T., Teh, S.J., 2013. Ingested plastic transfers hazardous chemicals to fish and induces hepatic stress. Sci Rep 3, 3263.

Rochman, C.M., Kurobe, T., Flores, I., Teh, S.J., 2014. Early warning signs of endocrine disruption in adult fish from the ingestion of polyethylene with and without sorbed chemical pollutants from the marine environment. Science of the Total Environment 493, 656-661.

Romeo, T., Pietro, B., Peda, C., Consoli, P., Andaloro, F., Fossi, M.C., 2015. First evidence of presence of plastic debris in stomach of large pelagic fish in the Mediterranean Sea. Mar Pollut Bull 95, 358-361.

Ryan, P.G., 1988. Effects of ingested plastic on seabird feeding: Evidence from chickens. Mar Pollut Bull 19, 125-128.

Sarasquete, C., Segner, H., 2000. Cytochrome P4501A (CYP1A) in teleostean fishes. A review of immunohistochemical studies. Sci Total Environ 247, 313-332.

Teuten, E.L., Saquing, J.M., Knappe, D.R., Barlaz, M.A., Jonsson, S., Bjorn, A., Rowland, S.J., Thompson, R.C., Galloway, T.S., Yamashita, R., Ochi, D., Watanuki, Y., Moore, C., Viet, P.H., Tana, T.S., Prudente, M., Boonyatumanond, R., Zakaria, M.P., Akkhavong, K., Ogata, Y., Hirai, H., Iwasa, S., Mizukawa, K., Hagino, Y., Imamura, A., Saha, M., Takada, H., 2009. Transport and release of chemicals from plastics to the environment and to wildlife. Philos Trans R Soc Lond B Biol Sci 364, 2027-2045.

Thompson, R.C., Olsen, Y., Mitchell, R.P., Davis, A., Rowland, S.J., John, A.W., McGonigle, D., Russell, A.E., 2004. Lost at sea: where is all the plastic? Science 304, 838.

Thompson, R.C., 2015. Microplastics in the Marine Environment: Sources, Consequences and Solutions, in: Bergmann, M., Gutow, L., Klages, M.,. (Eds.), Marine Anthropogenic Litter. Springer International Publishing, pp. 185-200.

Van Cauwenberghe, L., Janssen, C.R., 2014. Microplastics in bivalves cultured for human consumption. Environ Pollut 193, 65-70. 
Van Cauwenberghe, L., Claessens, M., Vandegehuchte, M.B., Janssen, C.R., 2015. Microplastics are taken up by mussels (Mytilus edulis) and lugworms (Arenicola marina) living in natural habitats. Environ Pollut 199, 10-17.

Von Moos, N., Burkhardt-Holm, P., Kohler, A., 2012. Uptake and effects of microplastics on cells and tissue of the blue mussel Mytilus edulis L. after an experimental exposure. Environ Sci Technol 46, 11327-11335.

Wright, S.L., Rowe, D., Thompson, R.C., Galloway, T.S., 2013a. Microplastic ingestion decreases energy reserves in marine worms. Curr Biol 23, R1031-1033.

Wright, S.L., Thompson, R.C., Galloway, T.S., 2013b. The physical impacts of microplastics on marine organisms: a review. Environ Pollut 178, 483-492.

Zitko, V., Hanlon, M., 1991. Another source of pollution by plastics: skin cleans with plastic scrubbers. Mar Pollut Bull 22, 41-42.

Zuur, A.F., Ieno, E.N., Walker, N.J., Saveliev, A.A. and Smith, G.M. Mixed Effets Models and Extensions in Ecology with R. Springer, New York, US. 2009. 
536 Table 1: Sequences of the primer pairs used for real-time PCR determination of the

537 transcript levels of several European sea bass genes used as housekeeping genes 538 (GAPDH, EF1 $\alpha$ ) or involved in detoxification (Cyp1a1) and anti-inflammatory (IL-1 $\beta$ ) 539 processes. \#: accession number taken from http://public540 contigbrowser.sigenae.org:9090/Dicentrarchus labrax/index.html; §: accession number 541 originated from http://www.ncbi.nlm.nih.gov/.

542

\begin{tabular}{ccc}
\hline $\begin{array}{c}\text { Gene } \\
\text { name }\end{array}$ & $\begin{array}{c}\text { Forward (F) } \\
\text { and Reverse (R) primers }\end{array}$ & Accession numbers \\
\hline Cyp1a1 & F: GTGCAGCTTCTGGACAATGA & AJ251913.p.d1.5 \# \\
& R: GATGGCACTGAGCTCAACAA & AJ866727.1 \\
EF1 $\boldsymbol{\alpha}$ & F: GCTTCGAGGAAATCACCAAG & \\
& R: CAACCTTCCATCCCTTGAAC & AY863148 \\
GAPDH & F: GAGGTCAAGGTTGAGGGTGA & AJ269472.1 \\
& R: CCAGTGGACTCAACCACGTA & \\
IL-1 $\boldsymbol{\beta}$ & F: GAAATGCAACATGAGCGAGA & \\
& R: CTCATTGTCAGTGGGTGGTG & \\
\hline
\end{tabular}




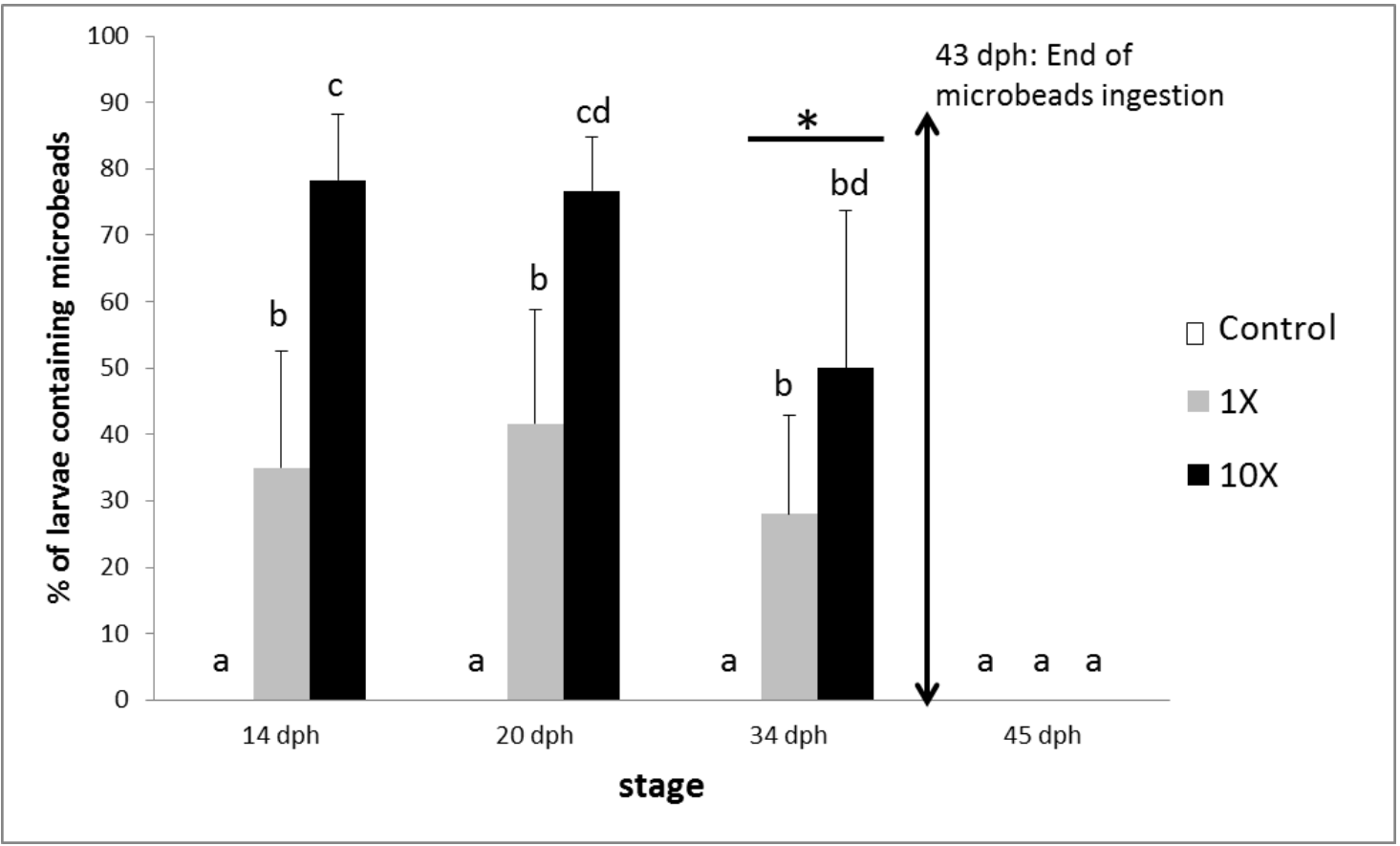

Figure 1: Percentage of European sea bass larvae containing fluorescent Polyethylene microbeads throughout the exposition phase $(7-43 \mathrm{dph})$ and 2 days after the end of exposure (45 dph) in the three experimental groups (white: control, light grey: $1 \mathrm{X}$, dark grey: 10X). Data values $=0$ for control group. Data are means, $n=6$ tanks $(20$ larvae analysed per tank) \pm SE. Asterisk indicates significant difference among stages. The letters $a, b, c$ and $d$ above the bar indicate homogenous subsets formed during post hoc multiple comparison tests at significant differences $(p<0.05)$ between experimental group during exposure time. 
a

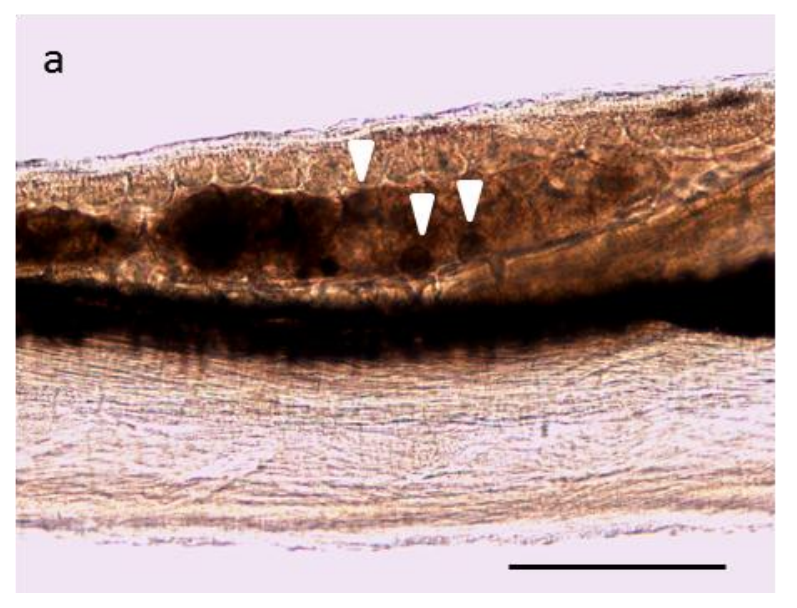

\section{b}

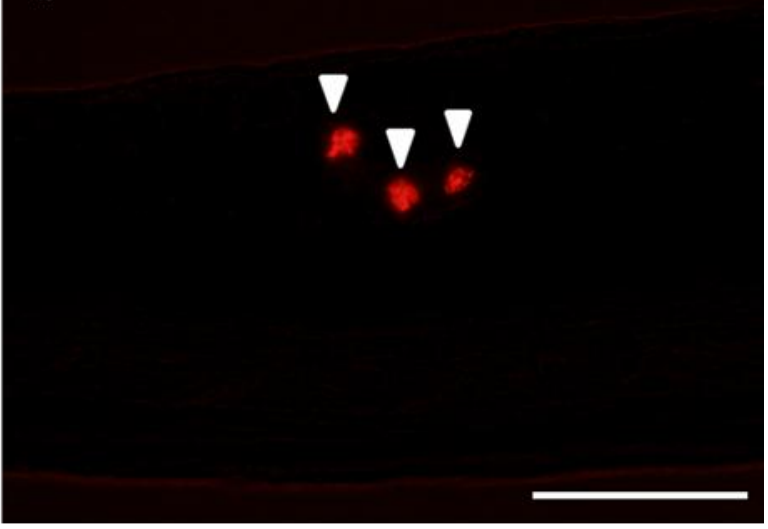

Figure 2: European sea bass larvae from experimental group $10 \mathrm{X}$ at $20 \mathrm{dph}$ containing three fluorescent Polyethylene microbeads (arrows) in its digestive tract. a: bright field; b: dark field. Scale bars represent $250 \mu \mathrm{m}$.

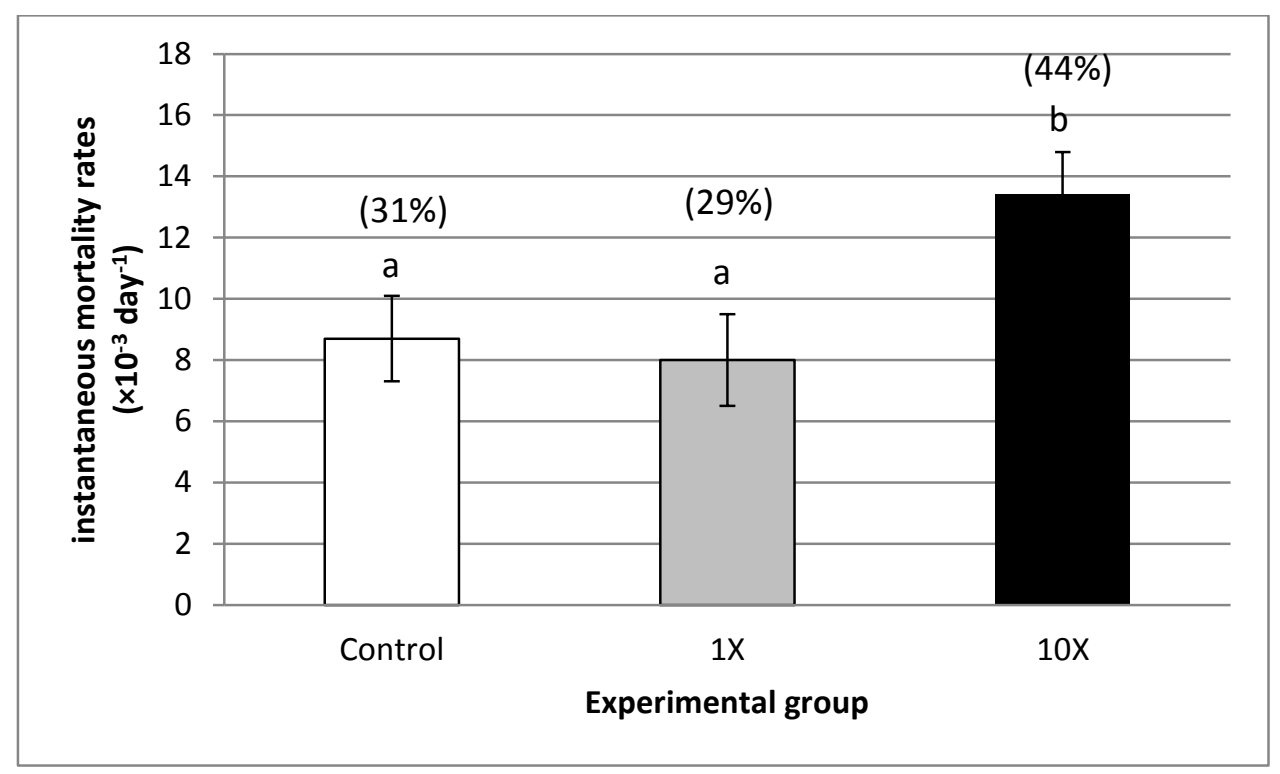

Figure 3: Effect of per os administration of polyethylene microbeads on the instantaneous mortality rates of European sea bass larvae. Data are means $(n=6$ tanks \pm SD). Statistical analysis based on negative binomial regression revealed higher larval instantaneous mortality rates in $10 \mathrm{X}$ group as compared to $\mathrm{C}$ and $1 \mathrm{X}$ groups. Cumulative mortality scores measured at $45 \mathrm{dph}$ are indicated in brackets. 


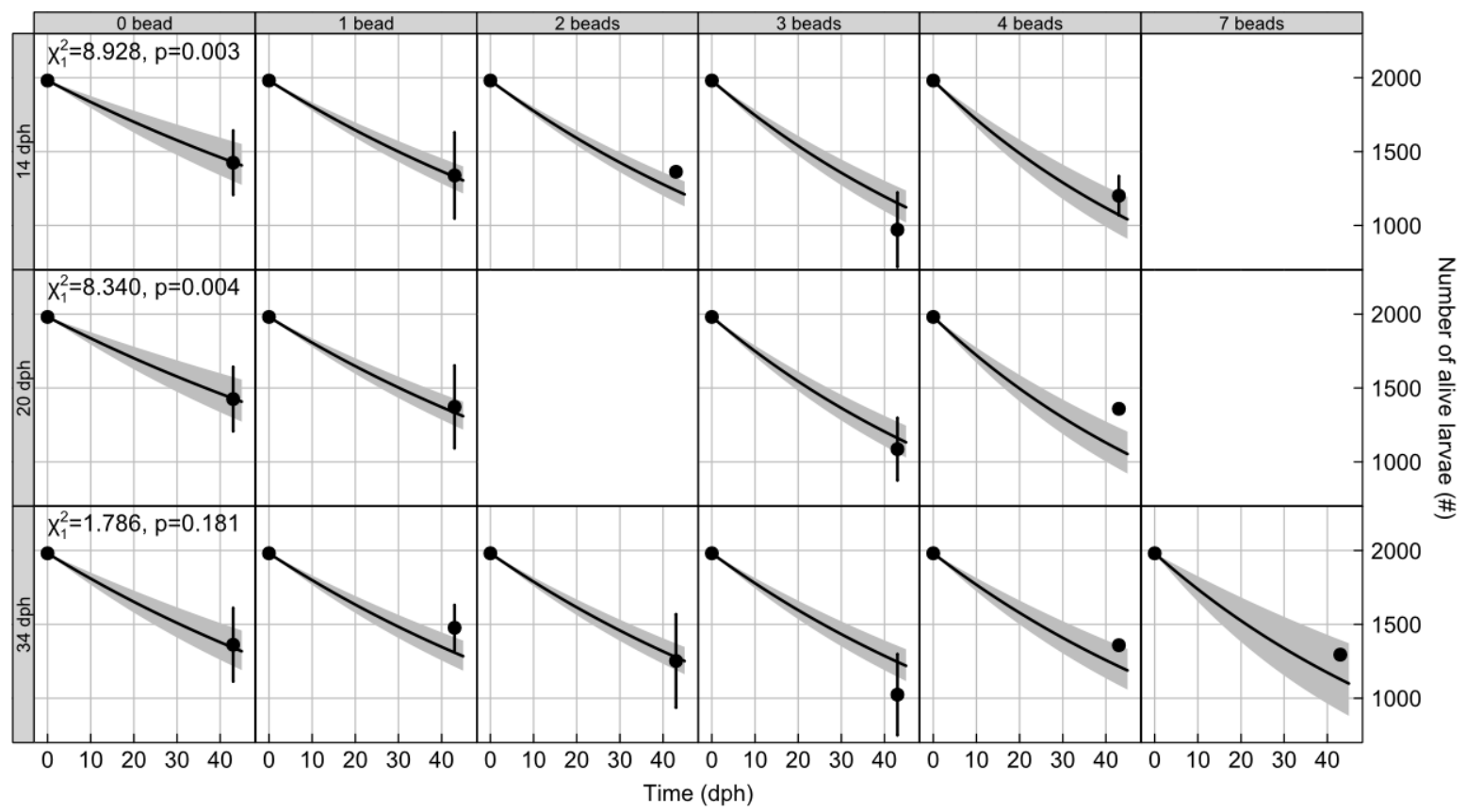

Figure 4: Effect of the number of polyethylene microbeads per individual on the mortality rate of European sea bass larvae. Rows correspond to the date $(14,20$ and 34 dph) of microbead scoring and columns to the observed average number of microbead scored per individual (from 0 to 7). Empty panels correspond to unobserved combinations of scoring date and scored number. Within each panel, points are observed mean numbers of alive larvae $\pm \mathrm{SE}$ at $\mathrm{O}$ and $45 \mathrm{dph}$, black curves represent the estimated decrease in the number of alive larvae with time by negative binomial regression, and shaded areas are the corresponding confidence intervals. Significance test ( $\chi^{2}$ statistic with degrees of freedom as subscript and p-value) for the effect of the number of microbead per larva on larval instantaneous mortality rate is given in the first panel of each row. 


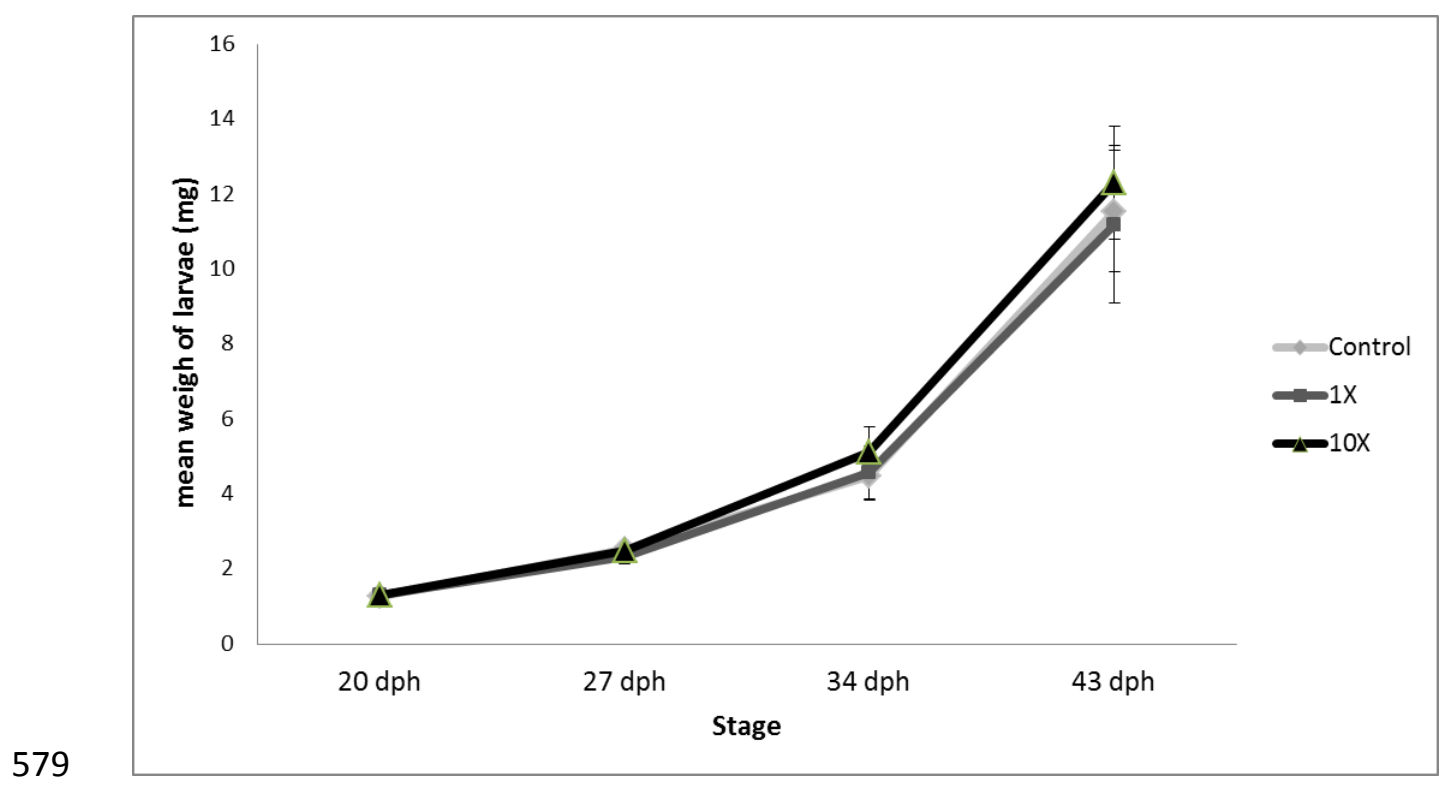

580 Figure 5: Growth of control and exposed European sea bass larvae by per os 581 administration of polyethylene microbeads. Data are means $\pm \mathrm{SE}, \mathbf{n}=\mathbf{3 0 0 - 3 6 0}$. 


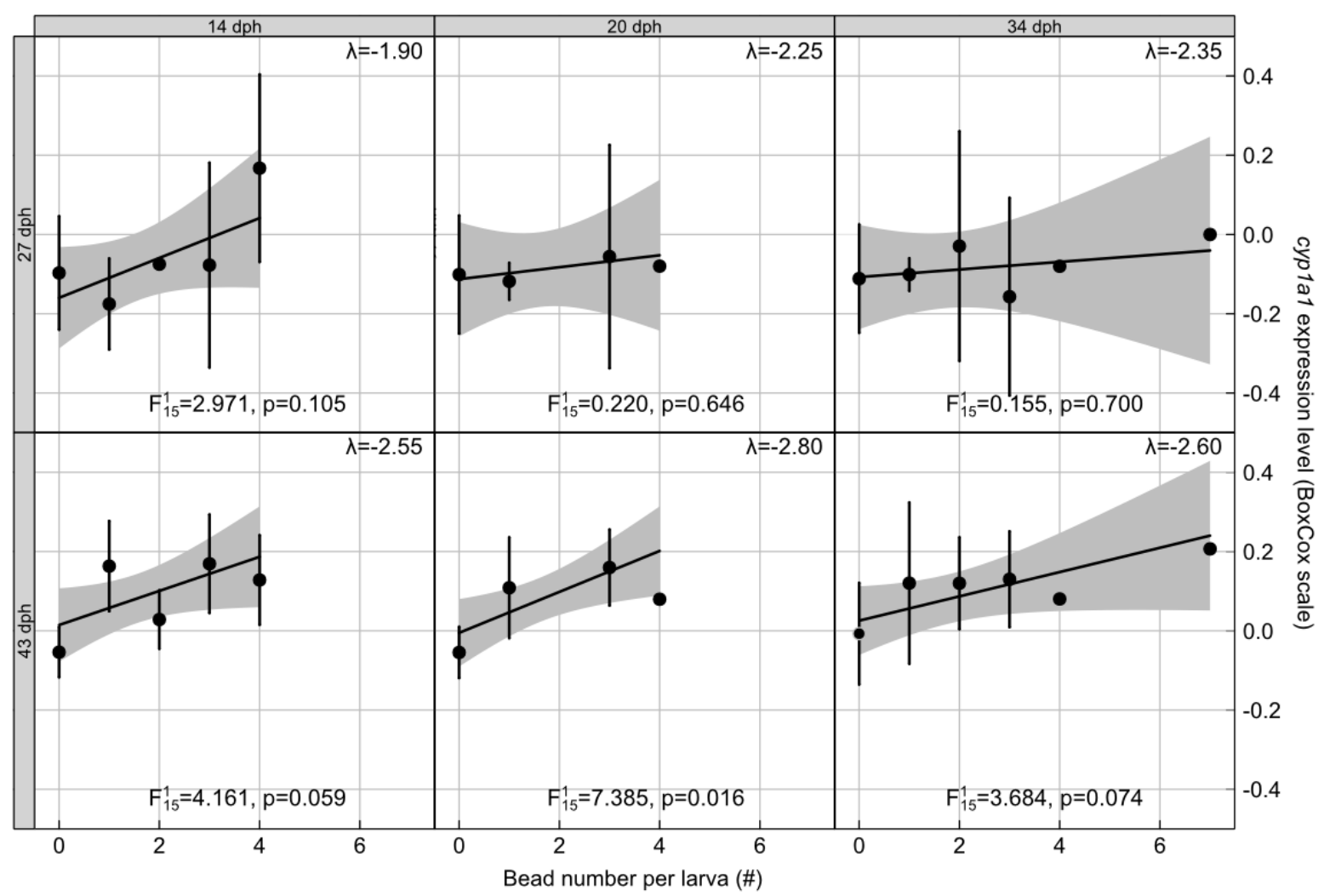

Figure 6: Effect of the number of polyethylene microbeads per individual on cypla1 gene expression. Rows correspond to the date (27 and 43 dph) of cypla1 expression measurement and columns to the date (14, 20 and $34 \mathrm{dph})$ of microbead scoring. Within each panel, points are observed mean cyplal expression level \pm SE (absence of SE corresponds to only one value observed) according to the average number of beads scored per larva, black curves represent the estimated increase in cypla1 expression level with the number of beads per larva by linear regression, and shaded areas are the corresponding confidence intervals. cyplal expression level is given on the Box-Cox scale $\left(y^{\prime}=\left(y^{\lambda}-1\right) / \lambda\right)$, with the value of the Box-Cox exponent $\lambda$ indicated within each panel (top right corner). Significance test (F statistic with numerator and denominator degrees of freedom as super- and subscript, respectively, and p-value) for the effect of the number of bead per larva on cypla1 expression is given at the bottom of each panel. 
Percentages of larvae containing microbeads were compared between groups throughout

614 exposure time by using a two-way logistic regression with Group (C, 1X, 10X) and Stage (14, 20,34 , and $45 \mathrm{dph}$ ) as factors, followed by a post hoc multiple comparison test (Hothorn et al. 2008). As data were slightly over-dispersed, a quasi-binomial distribution was used in order to include an over-dispersion parameter. Significance of the effects was tested by likelihood ratio tests between nested models respecting marginality of the effects that are supposed to follow an $\mathrm{F}$ distribution (instead of a $\chi^{2}$ distribution because of over-dispersion) under the null hypothesis (type II tests; Fox and Weisberg, 2011).

The effect of microbeads exposure on larval mortality was assessed by analyzing the trend of the number of alive larvae with time (the slope representing instantaneous mortality rate) using negative binomial regression with a logarithmic link function according to the following model:

$$
n(\mu, t)=n\left(\mu, t_{0}\right) \exp \left(-m(\mu)\left(t-t_{0}\right)\right)
$$

where $n(\mu, t)$ is the number of alive larvae at time $t$ for microbead concentration $\mu, m(\mu)$ is mortality rate for microbead concentration $\mu$, and $t_{0}$ is time at the start of the experiment i.e. $2 \mathrm{dph}$. The use of a negative binomial regression was justified by the over-dispersion of the data (Zuur et al. 2009). The effect of microbead concentration on mortality rate was modeled linearly $m(\mu)=\alpha_{0}+\alpha_{\mu}$ by considering the effect of either the diet group (Group) taken as a categorical variable $\alpha_{\mu}=\alpha_{\text {Group }}$ or the average number of beads per larva $\left(b_{S}\right)$ measured at various stages ( $S=14,20$ or $34 \mathrm{dph}$ ) taken as a continuous variable $\alpha_{\mu}=\alpha_{1} b_{S}$. Significance of the effect of microbead concentration was tested by likelihood ratio tests between nested models. For the categorical variable Group, the likelihood ratio test was followed by a post- 
635 hoc multiple comparison test (Hothorn et al. 2008) to assess which groups differed from one 636 another.

637 The potential impact of microbeads exposure on $I L-1 \beta$ and cyplal gene expression at 27 and 63843 dph was evaluated by both one-way ANOVA with Group (C, 1X, 10X) as explanatory 639 factor and linear regression against the average number of beads per larva $\left(b_{S}\right)$ measured at 640 various stages ( $S=14,20$ or $34 \mathrm{dph}$ ). Because of heteroscedasticity and non-normality of the 641 residuals, gene expression data were Box-Cox transformed before analyses.

642 Potential impact of microbeads exposure on body weight gain was assessed using analysis of 643 covariance (ANCOVA) with Stage (20, 27, 34 and 43dph) as a continuous covariable and 644 Group (C, 1X, 10X) as a factor. For ANCOVA, variables were checked for normality with the 645 Kolmogorov-Smirnov test and for equality of variances using the Levene test.

646 For all statistical analyses, p-values threshold for significance was fixed at 0.05.

647

648 